\title{
Cationic Polymerization of Phenylbutadienes. III. Cationic Polymerization of 2-Phenyl-1,3-butadiene*
}

\author{
Ryuzo Asami and Kan-ichi Hasegawa \\ Department of Synthetic Chemistry, Nagoya Institute of \\ Technology, Gokiso-cho, Showa-ku, Nagoya 466, Japan.
}

(Received June 19, 1975)

\begin{abstract}
Phenylbutadiene was polymerized by $\mathrm{SnCl}_{4}, \mathrm{BF}_{3} \mathrm{OEt}_{2}$, and $\mathrm{Ph}_{3} \mathrm{CSnCl}_{5}$ in ethylene dichloride. The kinetic study showed a rapid initiation in the cases of $\mathrm{SnCl}_{4}$ and $\mathrm{BF}_{3} \mathrm{OEt}_{2}$, but a rather slow initiation in the case of $\mathrm{Ph}_{3} \mathrm{CSnCl}_{5}$. The initial rate of polymerization in the cases of $\mathrm{SnCl}_{4}$ and $\mathrm{BF}_{3} \mathrm{OEt}_{2}$ or the maximum rate in the case of $\mathrm{Ph}_{3} \mathrm{CSnCl}_{5}$ was expressed as follows
\end{abstract}

$$
R_{\mathrm{p} 0}\left(R_{\mathrm{p} \max }\right)=k[\mathrm{M}]_{0}[\mathrm{C}]_{0}=k_{\mathrm{p}}[\mathrm{M}]\left[\mathrm{M}_{n} \oplus\right]
$$

The molecular weight of the polymers obtained in these cationic polymerizations was independent of concentrations of both monomer and catalyst; hence, the monomer chain transfer was proposed as a terminating reaction. By IR, UV, and NMR spectroscopies, it was shown that the microstructure of the polymers obtained in these cationic polymerizations was a 1,4-structure and about a half of the double bonds in the polymers was consumed by a novel cyclization whose scheme was proposed. The UV spectrum of the propagating species of 2-phenylbutadiene in the cationic polymerization was also found to be the same as in the case of 1-phenylbutadiene.

KEY WORDS 2-Phenylbutadiene / Cationic Polymerization / Poly(2-phenylbutadiene) / Rapid Initiation / Cyclization / Active Species / Monomer Chain Transfer /

The polymerizations of 2-phenyl-1,3-butadiene (2-PB) have been shown in several papers. ${ }^{1-7}$ The polymerization of 2-PB by Ziegler-type catalysts has been performed and the structure of the polymers obtained was determined. ${ }^{1,2}$ The high 1,4-cis polymers were obtained using iso$\mathrm{Bu}_{3} \mathrm{Al}-\mathrm{TiCl}_{4}{ }^{1}$ and $\mathrm{AlHCl}_{2}-\mathrm{OEt}_{2}-\mathrm{AlI}_{3}-\mathrm{TiCl}_{4}{ }^{2}$ as catalysts, and a polymer with 73-\% 1,4-trans structure was also reported for the former catalyst in benzene. It has also been reported that the complexed catalyst has given a polymer having a cyclic structure such as phenanthrene by dehydration. ${ }^{3}$ In studies of anionic polymerization of phenylbutadienes, one of us has already reported that 2-PB has been polymerized to living polymers by means of sodium-naphthalene in tetrahydrofuran (THF) or butyllithium in ben-

* A major part of this study was presented at the 20th Annual Meeting of the Society of Polymer Science, Japan, at Tokyo, May, 1971. See Abstracts, p 48. zene, and the polymer prepared had the high cis-1,4 structure; the microstructures of poly(2PB) prepared by alkyllithium in various solvents have also been discussed. ${ }^{4}$

In the cationic polymerization of 2-PB, the results obtained previously were only concerned with the polymer structure. Poly(2-PB) prepared by $\mathrm{SnCl}_{4}$ had about 50-\% 1,4-structure in olefin double bonds, but further details of the structure could not be shown because of a partial gelation of the polymers. ${ }^{5,6}$ Recently, Higashimura, et al., have reported the cationic polymerization of 2 $\mathrm{PB}$, showing results for the rate of polymerization, the structure of the polymer obtained, and the copolymerizations of styrene with ringsubstituted 2-phenylbutadienes.

In preceding papers, the present authors have reported the cationic polymerization of 1-phenylbutadiene ${ }^{8}$ and the initiation of phenylbutadienes by $\mathrm{Ph}_{3} \mathrm{CSnCl}_{5}{ }^{9}$ It has been shown that reactivity of phenylbutadienes toward trityl cations decreased in the following order at $25^{\circ} \mathrm{C}$ 
1-phenylbutadiene $>2$-phenylbutadiene $>$

1,1-diphenylbutadiene $>$ 1,2-diphenyl-

butadiene $>2$,3-diphenylbutadiene

The low activation entropy found for the reaction of 2-PB with $\mathrm{Ph}_{3} \mathrm{CSnCl}_{5}$ suggested that the reaction involved a more restricted intermediate than that of 1-phenylbutadiene in the transition state.

In this paper, we have investigated the kinetics of the polymerization of 2-PB and the structure of the polymers obtained in order to make clear the reactivity of 2-PB in cationic polymerization.

\section{EXPERIMENTAL}

\section{Materials}

2-PB was synthesized as described in the preceding paper. ${ }^{9}$ Catalysts and solvents obtained commercially were further purified by distillation on calcium hydride in a vacuum line.

\section{Procedures}

The experimental operations were carried out in a high vacuum technique, with air pressure less than $10^{-5} \mathrm{mmHg}$. The rate of polymerization was followed by means of dilatometry. UV and visible spectra of the solutions during polymerization were measured by use of the quarts cell shown in the preceding paper. ${ }^{8}$ The polymerization was stopped by addition of methanol which contained a small amount of aqueous ammonia; the mixture was then poured into a large excess of methanol. The polymers which precipitated were filtered, washed with methanol, and dried under vacuum. The intrinsic viscosities of the polymers obtained were measured at $30^{\circ} \mathrm{C}$ in toluene. IR and ${ }^{1} \mathrm{H}$ NMR spectra of the polymers obtained were also measured as described in the preceding paper. ${ }^{8}$

\section{RESULTS AND DISCUSSION}

\section{Polymerization of 2-Phenylbutadiene by Various Catalysts}

The time-conversion curves of the polymerization of 2-PB by $\mathrm{Ph}_{3} \mathrm{CSnCl}_{5}$ in ethylene dichloride (EDC) at $25^{\circ} \mathrm{C}$ are shown in Figure 1. The sigmoid curve of these time-conversion plots suggests a slow initiation. The maximum rates of polymerization calculated are shown in Table

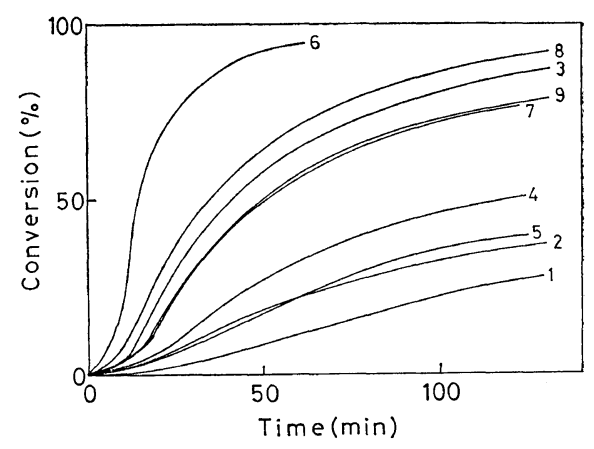

Figure 1. Time-conversion curves of polymerization of 2-PB catalyzed by $\mathrm{Ph}_{3} \mathrm{CSnCl}_{5}$ in EDC at $25^{\circ} \mathrm{C}:[\mathrm{M}]_{0}, 0.62-0.64 \mathrm{M} ;[\mathrm{C}]_{0}, 12.2 \mathrm{mM}(6), 3.1$ $\mathrm{m} M(3), 1.3 \mathrm{~m} M$ (4), $0.96 \mathrm{mM}$ (5); [C $]_{0}, 1.3-1.4$ $\mathrm{m} M ;[\mathrm{M}]_{0}, 1.09 M(1), 0.79 M(2), 0.64 M(4), 0.41 M$ (7), $0.25 M(8), 0.10 M(9)$.

Table I. Maximum rates of polymerization of 2-PB by $\mathrm{Ph}_{3} \mathrm{CSnCl}_{5}$ and intrinsic viscosities of the polymers ${ }^{a}$

\begin{tabular}{ccccc}
\hline $\begin{array}{c}\text { Run } \\
\text { no. }\end{array}$ & $\begin{array}{c}2-\mathrm{PB}, \\
\mathrm{mol} / l\end{array}$ & $\begin{array}{c}\mathrm{Ph}_{3} \mathrm{CSnCl}_{5}, \\
\mathrm{~mol} / l\end{array}$ & $\begin{array}{c}R_{\mathrm{p} m a x}, \\
\mathrm{~mol} / l \mathrm{~min}\end{array}$ & $\begin{array}{c}{[\eta],} \\
\mathrm{d} l / \mathrm{g}\end{array}$ \\
\hline 1 & 1.09 & $1.4 \times 10^{-3}$ & $3.0 \times 10^{-3}$ & 0.038 \\
2 & 0.79 & $1.3 \times 10^{-3}$ & $3.3 \times 10^{-3}$ & 0.043 \\
3 & 0.64 & $3.1 \times 10^{-3}$ & $1.4 \times 10^{-2}$ & 0.040 \\
4 & 0.64 & $1.3 \times 10^{-3}$ & $5.0 \times 10^{-3}$ & 0.037 \\
5 & 0.63 & $0.96 \times 10^{-3}$ & $2.9 \times 10^{-3}$ & 0.043 \\
6 & 0.62 & $12.2 \times 10^{-3}$ & $3.9 \times 10^{-3}$ & 0.038 \\
7 & 0.41 & $1.4 \times 10^{-3}$ & $7.4 \times 10^{-3}$ & 0.040 \\
8 & 0.25 & $1.4 \times 10^{-3}$ & $5.5 \times 10^{-3}$ & 0.035 \\
9 & 0.10 & $1.4 \times 10^{-3}$ & $2.0 \times 10^{-3}$ & 0.035 \\
\hline
\end{tabular}

a Solvent, EDC; temp, $25^{\circ} \mathrm{C}$.

I along with the intrinsic viscosity of the polymers. The dependency of these maximum rates on the initial monomer concentration is not simple, that is, at higher concentrations of monomer than around $0.5 \mathrm{~mol} / l$, the rates decreased as the monomer concentration increased. Such slow rates of initiation have already been reported in the preceding paper, where the initiation rate constant of 2-PB by $\mathrm{Ph}_{3} \mathrm{CSnCl}_{5}$ has been shown to be about one tenth of that of 1-PB. A stable $\pi$-complex formation between 2-PB and $\mathrm{SnCl}_{4}$ which competes with the initiation by $\mathrm{Ph}_{3} \mathrm{CSnCl}_{5}$ has been proposed; in such a case this complex formation will reduce the effective concentration of initiator, $\mathrm{Ph}_{3} \mathrm{CSnCl}_{5}$, and hence the rate of 


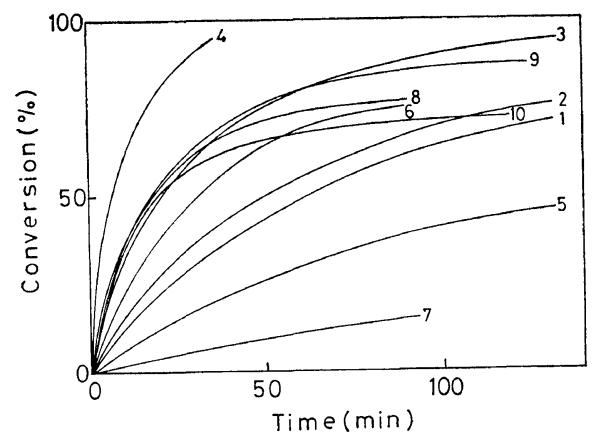

Figure 2. Time-conversion curves of polymerization of 2-PB catalyzed by $\mathrm{SnCl}_{4}$ in $\mathrm{EDC}$ at $25^{\circ} \mathrm{C}$ : $[\mathrm{M}]_{0}, 0.62-0.64 M ;[\mathrm{C}]_{0}, 12.9 \mathrm{mM}$ (4), $3.7 \mathrm{mM}$ (3), $2.0 \mathrm{mM}$ (6), $0.66 \mathrm{mM}$ (5), $0.15 \mathrm{mM}$ (7); [C] $]_{0} 2.0-$ $2.1 \mathrm{mM} ;[\mathrm{M}]_{0}, 0.86 M(1), 0.76 M(2), 0.62 M(6)$, $0.42 M(8), 0.26 M(9), 0.10 M(10)$.

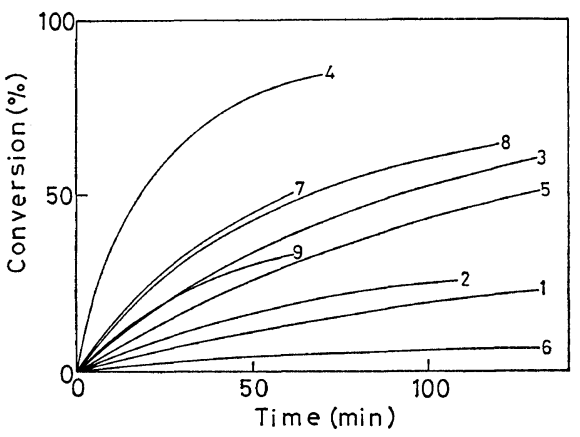

Figure 3. Time-conversion curves of polymerization of 2-PB catalyzed by $\mathrm{BF}_{3} \mathrm{OEt}_{2}$ in EDC at $25^{\circ} \mathrm{C}:[\mathrm{M}]_{0}, 0.62-0.64 \mathrm{M} ;[\mathrm{C}]_{0}, 19.1 \mathrm{mM}(4), 5.5$ $\mathrm{m} M$ (3), $1.8 \mathrm{~m} M$, (5), $0.44 \mathrm{mM}$ (6); [C], $1.8 \mathrm{~m} M$; $[\mathrm{M}]_{0}, 0.87 M(1) 0.77 M(2), 0.62 M(5), 0.42 M(7)$, $0.25 M(8), 0.10 M(9)$.

polymerization will be decreased at high monomer concentrations.

In Figures 2 and 3 are shown the time-conversion curves of polymerization of 2-PB catalyzed by $\mathrm{SnCl}_{4}$ and $\mathrm{BF}_{3} \mathrm{OEt}_{2}$, respectively. For both cases, the time-conversion curves are not sigmoid, in contrast with the case of $\mathrm{Ph}_{3} \mathrm{CSnCl}_{5}$, so that a slow initiation could not be suggested. The initial rates calculated from the initial slopes of the first-order plots of the time-conversion curves for the cases of $\mathrm{SnCl}_{4}$ and $\mathrm{BF}_{3} \mathrm{OEt}_{2}$ are shown in Tables II and III, respectively. The first-order plots of monomer concentration in the case of $\mathrm{SnCl}_{4}$ are shown in Figure 4: here a
Table II. Initial rates of polymerization of 2-PB by $\mathrm{SnCl}_{4}$ and intrinsic viscosities of the polymers ${ }^{a}$

\begin{tabular}{ccccc}
\hline $\begin{array}{c}\text { Run } \\
\text { no. }\end{array}$ & $\begin{array}{c}2-\mathrm{PB}, \\
\mathrm{mol} / l\end{array}$ & $\begin{array}{c}\mathrm{SnCl}_{4}, \\
\mathrm{~mol} / l\end{array}$ & $\begin{array}{c}R_{\mathrm{p} 0}, \\
\mathrm{~mol} / l \mathrm{~min}\end{array}$ & $\begin{array}{c}{[\eta],} \\
\mathrm{d} l / g\end{array}$ \\
\hline 1 & 0.86 & $2.0 \times 10^{-3}$ & $9.9 \times 10^{-3}$ & 0.046 \\
2 & 0.76 & $2.1 \times 10^{-3}$ & $1.1 \times 10^{-2}$ & 0.043 \\
3 & 0.64 & $3.7 \times 10^{-3}$ & $2.2 \times 10^{-2}$ & 0.038 \\
4 & 0.63 & $12.9 \times 10^{-3}$ & $8.0 \times 10^{-2}$ & 0.035 \\
5 & 0.62 & $0.66 \times 10^{-3}$ & $3.9 \times 10^{-3}$ & 0.039 \\
6 & 0.62 & $2.0 \times 10^{-3}$ & $1.5 \times 10^{-2}$ & 0.041 \\
7 & 0.62 & $0.15 \times 10^{-3}$ & $1.1 \times 10^{-3}$ & 0.032 \\
8 & 0.42 & $2.0 \times 10^{-3}$ & $1.5 \times 10^{-2}$ & 0.040 \\
9 & 0.26 & $2.0 \times 10^{-3}$ & $1.1 \times 10^{-2}$ & 0.036 \\
10 & 0.10 & $2.0 \times 10^{-3}$ & $4.4 \times 10^{-3}$ & 0.025 \\
\hline
\end{tabular}

a Solvent, EDC; temp, $25^{\circ} \mathrm{C}$.

Table III. Initial rates of polymerization of 2-PB by $\mathrm{BF}_{3} \mathrm{OEt}_{2}$ and intrinsic viscosities of the polymers ${ }^{a}$

\begin{tabular}{ccccc}
\hline $\begin{array}{c}\text { Run } \\
\text { no. }\end{array}$ & $\begin{array}{c}2-\mathrm{PB}, \\
\mathrm{mol} / l\end{array}$ & $\begin{array}{c}\mathrm{BF}_{3} \mathrm{OEt}_{2}, \\
\mathrm{~mol} / l\end{array}$ & $\begin{array}{c}R_{\mathrm{p} 0}, \\
\mathrm{~mol} / l \mathrm{~min}\end{array}$ & $\begin{array}{c}{[\eta],} \\
\mathrm{d} l / g\end{array}$ \\
\hline 1 & 0.87 & $1.8 \times 10^{-3}$ & $2.5 \times 10^{-3}$ & 0.040 \\
2 & 0.77 & $1.8 \times 10^{-3}$ & $2.9 \times 10^{-3}$ & 0.040 \\
3 & 0.64 & $5.5 \times 10^{-3}$ & $5.1 \times 10^{-3}$ & 0.037 \\
4 & 0.63 & $19.1 \times 10^{-3}$ & $2.3 \times 10^{-2}$ & 0.032 \\
5 & 0.62 & $1.8 \times 10^{-3}$ & $3.3 \times 10^{-3}$ & 0.036 \\
6 & 0.62 & $0.44 \times 10^{-3}$ & $2.7 \times 10^{-4}$ & 0.035 \\
7 & 0.42 & $1.8 \times 10^{-3}$ & $4.5 \times 10^{-3}$ & 0.035 \\
8 & 0.25 & $1.8 \times 10^{-3}$ & $2.4 \times 10^{-3}$ & 0.036 \\
9 & 0.10 & $1.8 \times 10^{-3}$ & $1.9 \times 10^{-3}$ & 0.032 \\
\hline
\end{tabular}

a Solvent, EDC; temp, $25^{\circ} \mathrm{C}$.

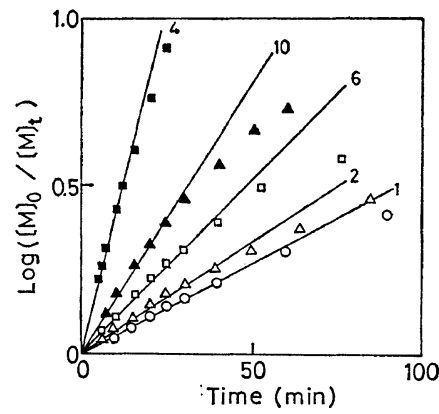

Figure 4. The first-order plots of polymerization of 2-PB catalyzed by $\mathrm{SnCl}_{4}$ in Figure 2: $\bigcirc(1)$; $\triangle(2) ; \boldsymbol{\square}(4) ; \square(6) ; \boldsymbol{\Delta}(10)$.

linear relation could be seen, but a deviation appeared at high conversions of about $70 \%$. Similar results have been indicated in the case 
of 1-PB. It is reasonable that the deviation should be ascribed to a chain transfer to the polymer, which forms more stable cations than the propagating carbonium ion.

The maximum rate calculated in the case of $\mathrm{Ph}_{3} \mathrm{CSnCl}_{5}$ and the initial rates of polymerization of 2-PB by $\mathrm{SnCl}_{4}$ and $\mathrm{BF}_{3} \mathrm{OEt}_{2}$ are plotted against monomer concentrations and initial concentrations of catalysts in Figures 5 and 6, respectively. As can be seen in Figure 6, the initial rates of polymerization were proportional to the initial

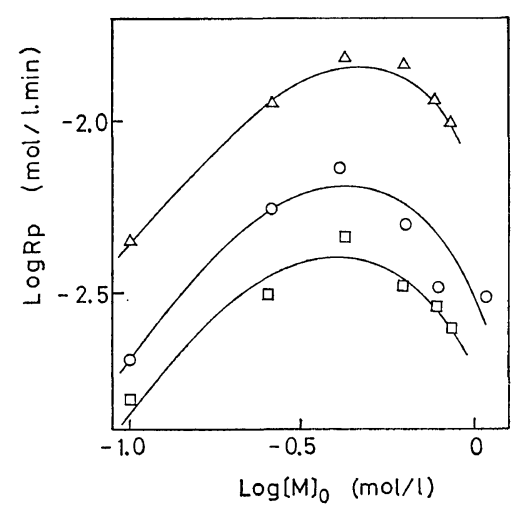

Figure 5. Dependence of $[\mathrm{M}]_{0}$ on $R_{\mathrm{p} 0}\left(R_{\mathrm{p} \max }\right.$ in the case of $\mathrm{Ph}_{3} \mathrm{CSnCl}_{5}$ ). Log-log plots of the initial monomer concentration and the initial rate (the maximum rate in the case of $\mathrm{Ph}_{3} \mathrm{CSnCl}_{5}$ ) of polymerization: $\triangle, \mathrm{SnCl}_{4} ; \square, \mathrm{BF}_{3} \mathrm{OEt}_{2} ; \bigcirc, \mathrm{Ph}_{3} \mathrm{CSnCl}_{5}$.

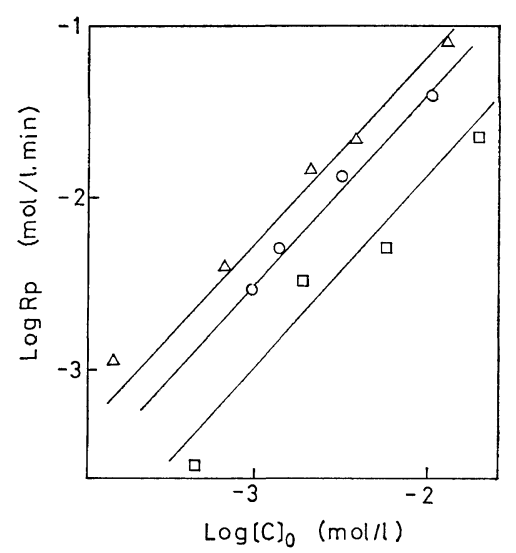

Figure 6. Dependence of $[\mathrm{C}]_{0}$ on $R_{\mathrm{p} 0}\left(R_{\mathrm{p} \max }\right.$ in the case of $\mathrm{Ph}_{3} \mathrm{CSnCl}_{5}$ ). Log-log plots of the catalyst concentration and the initial rate (maximum rate in the case of $\mathrm{Ph}_{3} \mathrm{CSnCl}_{5}$ ) of polymerization: $\Delta$, $\mathrm{SnCl}_{4} ; \square, \mathrm{BF}_{3} \mathrm{OEt}_{2} ; \bigcirc, \mathrm{Ph}_{3} \mathrm{CSnCl}_{5}$. concentrations of catalysts in all cases of $\mathrm{SnCl}_{4}$, $\mathrm{BF}_{3} \mathrm{OEt}_{2}$, and $\mathrm{Ph}_{3} \mathrm{CSnCl}_{5}$. The dependency of the initial rate on the monomer concentration was unique, as has been described above in the case of $\mathrm{Ph}_{3} \mathrm{CSnCl}_{5}$. In all cases of $\mathrm{SnCl}_{4}, \mathrm{BF}_{3}$ $\mathrm{OEt}_{2}$, and $\mathrm{Ph}_{3} \mathrm{CSnCl}_{5}$, a proportional relation between the initial rates and the monomer concentrations could be seen at concentrations lower than $c a .0 .5 \mathrm{~mol} / l$.

The intrinsic viscosities of the polymers obtained are shown in Tables I, II, and III, and it can be concluded that the molecular weight of the polymers is independent of both the monomer concentration and the catalyst concentration. The fact suggests a predominant chain transfer to monomer as a terminating reaction.

From these results the rate of polymerization could be expressed in the following equations. In the cases of $\mathrm{SnCl}_{4}$ and $\mathrm{BF}_{3} \mathrm{OEt}_{2}$, which involved a rapid initiation, eq 1 could be applied for the initial rates.

$$
R_{\mathrm{p} 0}=k[\mathrm{M}]_{0}[\mathrm{C}]_{0}=k_{\mathrm{p}}[\mathrm{M}]\left[\mathrm{M}_{n}{ }^{\oplus}\right]
$$

However, in the case of $\mathrm{Ph}_{3} \mathrm{CSnCl}_{5}$, because of the slow initiation, the maximum rate has appeared after $10-20 \mathrm{~min}$, indicating the completion. Hence, for this maximum rate eq 2 could be applied.

$$
R_{\mathrm{p} \text { max }}=k[\mathrm{M}]_{0}[\mathrm{C}]_{0}=k_{\mathrm{p}}[\mathrm{M}]\left[\mathrm{M}_{n}^{\oplus}\right]
$$

In both equations $\left[\mathrm{M}_{n}^{\oplus}\right]$ was not determined directly, but in eq 1 it was assumed that $\left[\mathrm{M}_{n}{ }^{\oplus}\right]$ was approximately equal to $\left[\mathrm{C}_{0}\right.$, since the initiation was found to be rapid. Hence $k_{\mathrm{p}}$ was calculated as $k_{\mathrm{p}}\left(25^{\circ} \mathrm{C}\right)=22 \mathrm{l} / \mathrm{mol} \mathrm{min}$. This value is twice as large as that of $1-\mathrm{PB}$, where $k_{\mathrm{p}}=10$ $l / \mathrm{mol} \mathrm{min}$.

The monomer reactivity of 1-PB was found to be larger than that of 2-PB after further study of the copolymerization. ${ }^{10}$ Therefore, the fact that the $k_{\mathrm{p}}$ of 2-PB is twice as large as that of 1-PB means the carbonium ion produced from $2-\mathrm{PB}$ is much more reactive than that of 1-PB. In anionic polymerization, the authors found that the $k_{\mathrm{p}}$ of 2-PB is larger than that of 1-PB in benzene. ${ }^{11}$

After consideration of the kinetic data, the molecular weight, and the structure of the polymers, a total scheme of cationic polymerization 
of 2-PB in EDC was proposed as follows. It is the same as that of 1-PB except for the $\pi$-complex formation between 2-PB and catalysts in the initiation step.

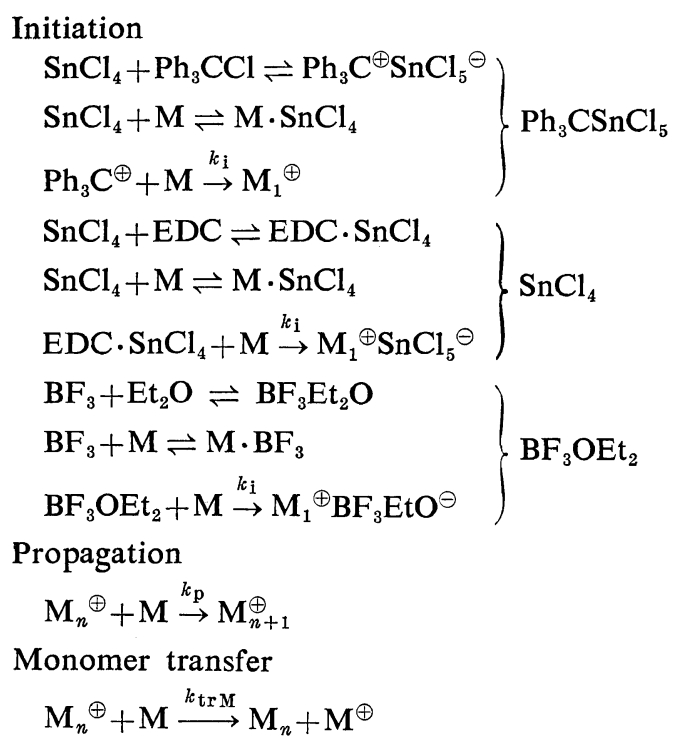

Polymer transfer

$$
\begin{aligned}
& \mathbf{M}_{n}^{\oplus}+\mathbf{P} \stackrel{k_{\text {tr } \mathrm{P}}}{\longrightarrow} \mathrm{M}_{n}+\mathrm{P}^{\oplus} \\
& \text { Cyclization } \\
& \mathrm{P}^{\oplus} \longrightarrow \mathrm{P}+\mathrm{H}^{\oplus}
\end{aligned}
$$

In this scheme, monomer transfer is described as the same reaction as in the case of 1-PB, producing an indenyl end.

In case of 2-PB<smiles>[M]C[C-]C(CC)c1ccccc1</smiles><smiles></smiles>

In case of $1-\mathrm{PB}$

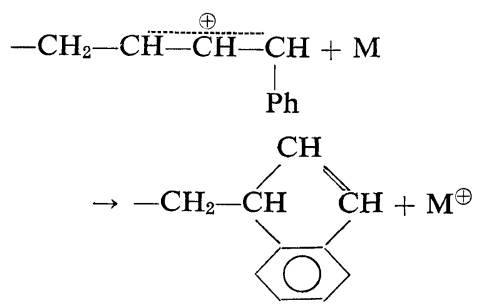

The polymer transfer and cyclization will be discussed in a later section.

Structure of Poly(2-phenylbutadiene) Obtained in Cationic Polymerization

The microstructure of poly(2-phenylbutadiene) polymerized by the cationic catalysts was determined qualitatively by the IR spectrum of these polymers, then quantitatively by the NMR and UV spectra.

A weak absorption band at $840 \mathrm{~cm}^{-1}$ due to an out-of-plane vibration of trisubstituted olefinic proton was observed in the IR spectra of the soluble white powder of poly(2-PB) obtained by $\mathrm{Ph}_{3} \mathrm{CSnCl}_{5}, \mathrm{SnCl}_{4}$, and $\mathrm{BF}_{3} \mathrm{OEt}_{2}$ in $\mathrm{EDC}$, whereas no absorption bands at 990,910 , and $890 \mathrm{~cm}^{-1}$ were observed in the IR spectra of these polymers. Therefore, it is suggested from these results that 2-PB was polymerized mainly in the fashion of 1,4-propagation.

The NMR spectrum of poly(2-PB) prepared by $\mathrm{SnCl}_{4}$ is shown in Figure 7, together with that of poly(2-PB) polymerized by $\mathrm{Na}$-naphthalene in tetrahydrofuran (THF) for comparison. The signals at $2.9,4-5$, and $7-9 \tau$ were assigned to phenyl, olefinic, and methyne-methylene protons, respectively. From the ratios of the peak areas of these proton signals based on a 1,4-structure, the olefinic double bond of poly(2$\mathrm{PB})$ obtained by the various cationic catalysts is shown to be isomerized to a saturated bond to an extent of about $50 \%$. This was also supported by the large increase of the area of methynemethylene proton signal. The poly(2-PB) obtained by $\mathrm{Na}$-naphthalene in Figure 7 has already been shown to be a cis-1,4 structure and no isomerization was observed in the NMR spectrum. ${ }^{4}$

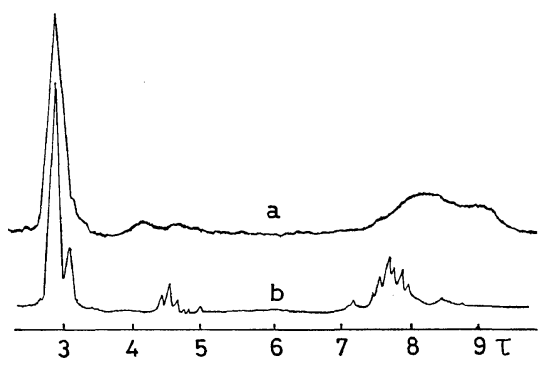

Figure 7. NMR spectra of poly(2-PB): a, poly(2$\mathrm{PB}$ ) obtained by $\mathrm{SnCl}_{4}$ in $\mathrm{EDC} ; \mathrm{b}$, poly $(2-\mathrm{PB})$ obtained by $\mathrm{Na}-$ naphthalene in THF. 
The UV spectra of poly(2-PB) obtained by the cationic catalysts showed a strong absorption peak at $245 \mathrm{~nm}$ with $\varepsilon_{\max }=4000-6000$; on the other hand the polymer prepared by anionic initiator showed the same peak at $245 \mathrm{~nm}$ with $\varepsilon_{\max }=c a$. 10000. Hence, from the results of UV spectra it was reconfirmed that about a half of the olefinic double bonds were consumed by a side reaction.
Although we had proposed a cyclization of pendant double bonds in the case of 1-PB in the preceding paper, a novel cyclization in 1,4-structure of 2-PB polymer was proposed as isomerization reaction which is responsible for consumption of double bonds in the polymer without cross-linking. This cyclization was initiated by polymer transfer, then the total reaction proceeds as follows

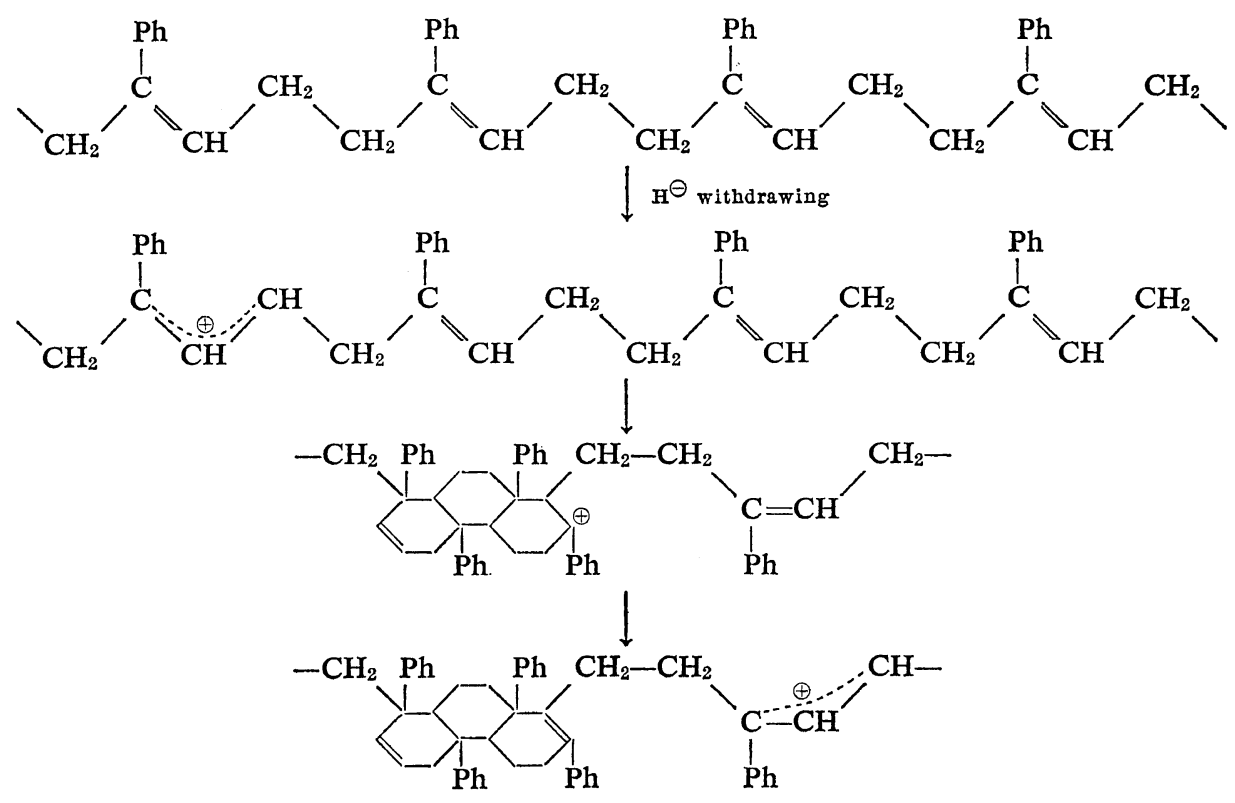

This cyclization would be quite similar to the intra-inter polymerization of 1,5-hexadiene derivatives, which is well known as a cyclopolymerization. Furthermore, the above scheme will explain the consumption of double bonds as high as $50 \%$, as was found in the experiments. The cyclization which involves a hydro-phenanthrene structure has already been reported in the polymerization of 2-PB by complex catalysts. ${ }^{3}$

Visible Spectra in the Cationic Polymerization of 2-Phenylbutadiene

In Figures 8 and 9 are shown typical UV spectra observed in the course of the cationic polymerization of 2-PB catalyzed by $\mathrm{SnCl}_{4}$ and $\mathrm{BF}_{3} \mathrm{OEt}_{2}$ in EDC, respectively. Two absorption peaks are seen in the visible region of both UV spectra. There had been no absorption peak in the visible region in the initial stage of polymerization, but a peak emerged at $545 \mathrm{~nm}$ as the polymerization proceeded, then another peak was. observed at $488 \mathrm{~nm}$ in the final stage of polymerization.

For the same reason as described in the discussion of the visible spectra observed in the

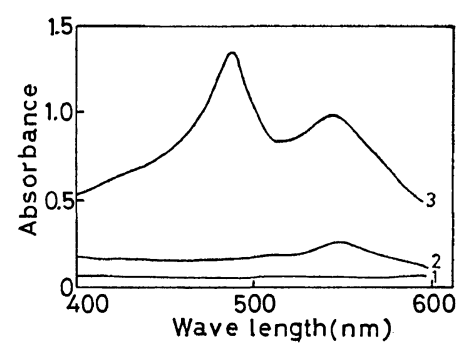

Figure 8. Visible absorption spectra observed during the polymerization of 2-PB by $\mathrm{SnCl}_{4}$ in EDC at room temperature: $[\mathrm{M}]_{0}, 0.629 \mathrm{M} ;[\mathrm{C}]_{0}, 8.9 \mathrm{mM}$; path length, $0.199 \mathrm{~cm}$; polymerization time, $1 \mathrm{~min}$ (1), $15 \mathrm{~min} \mathrm{(2),} 70 \mathrm{~min}(3)$. 
Cationic Polymerization of Phenylbutadienes. III.

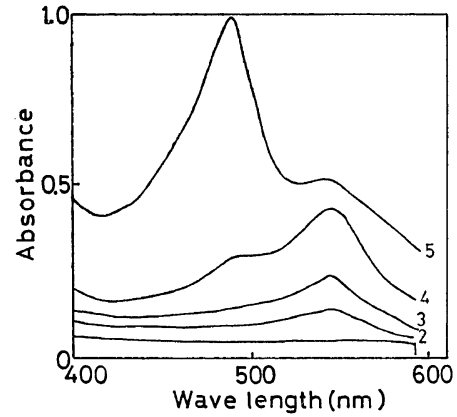

Figure 9. Visible absorption spectra observed during the polymerization of 2-PB by $\mathrm{BF}_{3} \mathrm{OEt}_{2}$ in EDC at room temperature: $[\mathrm{M}]_{0}, 0.626 \mathrm{M} ;[\mathrm{C}]_{0}$, $48.2 \mathrm{mM}$; path length, $0.199 \mathrm{~cm}$; polymerization time, $2 \mathrm{~min}(1), 20 \mathrm{~min} \mathrm{(2),} 1 \mathrm{hr}(3), 3 \mathrm{hr}(4), 2$ day (5).

polymerization of 1-PB in the preceding paper, it is also indicated that the absorption at $545 \mathrm{~nm}$ could be assigned to an indenyl cation formed by hydride-withdrawing from an indenyl end which was formed by monomer-transfer termination, as shown in the above section. This absorption peak was observed at $570 \mathrm{~nm}$ in the spectrum of 1-PB because the positions on the indenyl end from which a hydrogen has to be withdrawn are different in the case of 1-PB and 2-PB, as has been shown in the above section. The peak at $488 \mathrm{~nm}$ could be assigned to a 3phenylallyl-type cation formed by hydride-withdrawing from a 1,4-structure of the polymer as follows<smiles>C/C=C/[C](CCCCC=C(CC)c1ccccc1)c1ccccc1</smiles>

The initiation of cyclization of double bonds in polymer with this polymer cation has already been indicated above.

\section{REFERENCES}

1. A. Z. Shikhmamedebekova and S. I. SodykhZada, Azerb. Khim. Zh., 73 (1962).

2. (a) W. Marconi, A. Mazzei, G. Lugli, and M. Bruzzone, J. Polym. Sci., Part C, No., 16, 805 (1967). (b) J. K. Stille and E. D. Vessel, ibid, 49, 419 (1961).

3. E. I. du Pont de Nemours \& Co., Berg. Patent 623940, Apr. 23, 1963; U. S. Appl. Oct. 24, 1961; C.A., 58, 12133f (1960).

4. R. Asami and A. Shoji, Asahi Garasu Kogyo Gijutsu Shorei-Kai Kenkyu Hokoku, 12, 505 (1966), C.A., 68, 50119v (1968).

5. P. de Radzitzki and G. Smets, Bull. Soc. Chim. Berg., 62, 320 (1953).

6. P. de Radzitzki, M. C. de Wilde, and G. Smets, J. Polym. Sci., 13, 477 (1954).

7. T. Masuda, T. Mori, and T. Higashimura, ibid., Polym. Chem. Ed., 12, 2065 (1974).

8. R. Asami, K. Hasegawa, and T. Onoe, Polymer J., 8, 43 (1976).

9. R. Asami and K. Hasegawa, ibid., 8, 53 (1976).

10. R. Asami and K. Hasegawa, to be published.

11. R. Asami, K. Makino, and O. Kusudo, to be published. 